Article

\title{
On the Hydrodynamic Geometry of Flow-Through versus Restricted Lagoons
}

\author{
Nikolaos Th. Fourniotis ${ }^{1,2}$, ${ }^{\text {, Georgios M. Horsch }}{ }^{1}$ and Georgios A. Leftheriotis ${ }^{1}$ \\ 1 Department of Civil Engineering, University of Patras, University Campus, 26500 Patras, Greece; \\ ghorsch@upatras.gr (G.M.H.); gleytheriot@upatras.gr (G.L.A.) \\ 2 Department of Civil Engineering, Technological Educational Institute of Western Greece, \\ Megalou Alexandrou 1, 26334 Patras, Greece \\ * Correspondence: nfou@upatras.gr; Tel.: +30-2610-996519
}

Received: 19 January 2018; Accepted: 17 February 2018; Published: 25 February 2018

\begin{abstract}
The classification of a lagoon as a restricted lagoon is shown to depend not solely on its geometry but also on the tidal hydraulics. By numerically simulating the tidal exchange of two lagoons of similar geometrical dimensions, the Nidova lagoon and the Papas lagoon, in Western Greece, subject to very similar tidal forcing, applied to the two tidal inlets in the first case and three in the second, very different residence times are found, namely 2.5 days for the Nidova and 25-30 days for the Papas lagoon. This large difference is attributed to the fact that whereas the Papas lagoon functions as a typical restricted lagoon, in which the water renewal is achieved by mixing in the lagoon of the tidal prism water exchanged within a tidal cycle, the Nidova lagoon functions as a flow-through system because of the differential arrival of the tide at its two tidal inlets. It is suggested that this way of enhancing the flushing rate of a lagoon be considered, whenever possible, when creating a new tidal inlet to the lagoon.
\end{abstract}

Keywords: flow-through system; tidal inlets; residence time; coastal lagoon; MIKE 3 FM (HD \& TR); MIKE 21 FM (HD)

\section{Introduction}

Coastal lagoons are particularly important for fisheries and extensive or intensive aquaculture in many areas of the world, since marine fish species migrate towards lagoons, which provide favorable conditions for feeding and shelter [1]. Mediterranean lagoons, specifically, are important for aquaculture activities, and make a crucial contribution to the fishery economies in many countries. In Greek waters, important fishing and extensive aquaculture activities have been developed in the majority of lagoons (30 in the Aegean and 46 on the Ionian coast), occupying a total area of about 34,500 ha [2]. The fishery exploitation is based on traditional barrier fish traps. These are permanent entrapment devices and the catches are based on the species-specific inshore-offshore seasonal or ontogenic fish migration [3]. The majority of these extensive lagoon systems are located in western and northern Greece. The largest is the Messolonghi lagoonal complex located in western Greece, comprising six lagoons. The Messolonghi lagoon system covers about 15,000 ha [4] (p. 97), while the Papas lagoon (Araxos Cape, Achaia, Greece) has a mean size of 4500 ha [5].

In recent years many lagoon ecosystems have been affected by natural and mostly anthropogenic influences, e.g., hydrologic and hydrodynamic alterations, sources of pollution, sedimentation of tidal inlets/mouths, and regional infrastructure work. These changes gradually lead to alterations in the physical, chemical, and biochemical parameters of these complex ecosystems, which in turn may directly affect fish production and ecosystem dynamics [6,7]. The concentration of the corresponding substances in the lagoon ecosystems is generally dependent on hydrodynamic circulation and water renewal time, which are the crucial factors for decisions with regard to lagoon restoration design and 
management actions, aiming at the improvement of environmental conditions and fishery exploitation. An innovative method of data analysis has been presented in recent studies, focusing on similar coastal basins in Southern Italy [8,9]. The aim of these studies was to interpret hydrodynamic processes associated with these water bodies by identification and evaluation of hydrodynamic and meteorological data.

Among the physical parameters that affect the water quality of coastal lagoons, renewal of water has long been identified as a key parameter and has been made the basis of the early classification by Kjerfve [10] in choked, restricted, and leaky systems according to the degree of water exchanged with the adjacent coastal ocean. More recently, the water renewal time has been proposed as the basis for the classification of lagoons [11]. As a result of the importance of water renewal in lagoons, the creation of new artificial tidal inlets has been proposed and applied as a solution in several instances (see e.g., [12]).

The question then arises: is the amount of water exchanged in each tidal cycle the basic parameter-with all other parameters kept constant-determining the flushing time? Or, to rephrase the question, are two lagoons of similar dimensions and under the same tidal forcing expected to have similar flushing rates, or is it possible to have widely varying differences in flushing rates? The answer is provided by a real-life example of two lagoons situated in Western Greece, of similar dimensions and under very similar tidal forcing, namely the Nidova lagoon, part of the complex of the wider Messolonghi lagoon, and the Papas lagoon, both communicating with the Gulf of Patras. The former has a flushing rate on the order of a few days and the latter of over a month. In what follows, we analyze why the former, having only two tidal inlets, does not behave as a typical, restricted lagoon, as one might expect from mere inspection of its geometry, because the hydrodynamics circumvent, so to speak, the topography and render the lagoon a flow-through basin, whereas the latter, having three tidal inlets, behaves like a typical restricted lagoon and, possibly as a result, suffers recurring dystrophic crises.

\section{Materials and Methods}

\subsection{Description of the Study Areas}

The Nidova lagoon is embedded between the Messolonghi (south) and the Aetoliko (north) greater lagoons (Figure 1a). The lagoon is approximately $1.5 \mathrm{~km}^{2}$ in surface area, with a mean depth of $1.20 \mathrm{~m}$ and a maximum depth of $3 \mathrm{~m}$ at the western part of the basin. It is elongated in plan view, $2000 \mathrm{~m}$ long, approximately, with a perimeter of $5000 \mathrm{~m}$. The lagoon communicates to the north with the deeper Aetoliko lagoon via arc stone bridges, while to the south it is connected to the Messolonghi lagoon by a dredged trench (i.e., an underwater channel that is deeper than its surrounding waters) approximately $50 \mathrm{~m}$ wide, $1000 \mathrm{~m}$ long, and 1-3 m deep at mean lagoon level. At the western part of the lagoon an embankment with a road on it exists, linking the city of Aetoliko with the Dolmas islet in the south, where the Waste Water Treatment Plant of Aetoliko City operates. This embankment precludes exchange of Nidova waters with the Messolonghi lagoon waters from the west, so that the exchange between Nidova and Messolonghi takes place exclusively south of Nidova.

Tidal water enters from the Gulf of Patras to the Messolonghi lagoon from the south, and proceeds to Nidova through the dredged trench, while continuing to move into the Messolonghi lagoon, in parallel to the embankment up to the Aetoliko lagoon, and enters the Aetoliko lagoon through the arc stone bridges. The Nidova lagoon communicates with the Aetoliko lagoon (in the north) though the continuation of the arc stone bridges. During the last few years phytoplankton biomass blooms have formed in the restricted Nidova basin and cover almost the entire surface of the basin during the spring and early summer.

The Papas Lagoon is embedded within the northwestern coast of the Peloponnese, adjacent to the Gulf of Patras (Figure 1b). The lagoon is of elongated shape, with its main axis along the NW-SE direction. It is $5 \mathrm{~km}$ long, $1 \mathrm{~km}$ wide on average, and covers an area of about $6.2 \mathrm{~km}^{2}$ [13]. It is a deep water body, having a mean depth of $1.8 \mathrm{~m}$ and a maximum depth of $5 \mathrm{~m}$. It is connected to the Gulf of Patras with three stable tidal inlets, the length and width of which lie within 160-260 m and 25-50 m, 
respectively. During the winter, it is supplied with fresh water by a small draining stream discharging into the lagoon's southeastern part, which borders cultivated land [14].
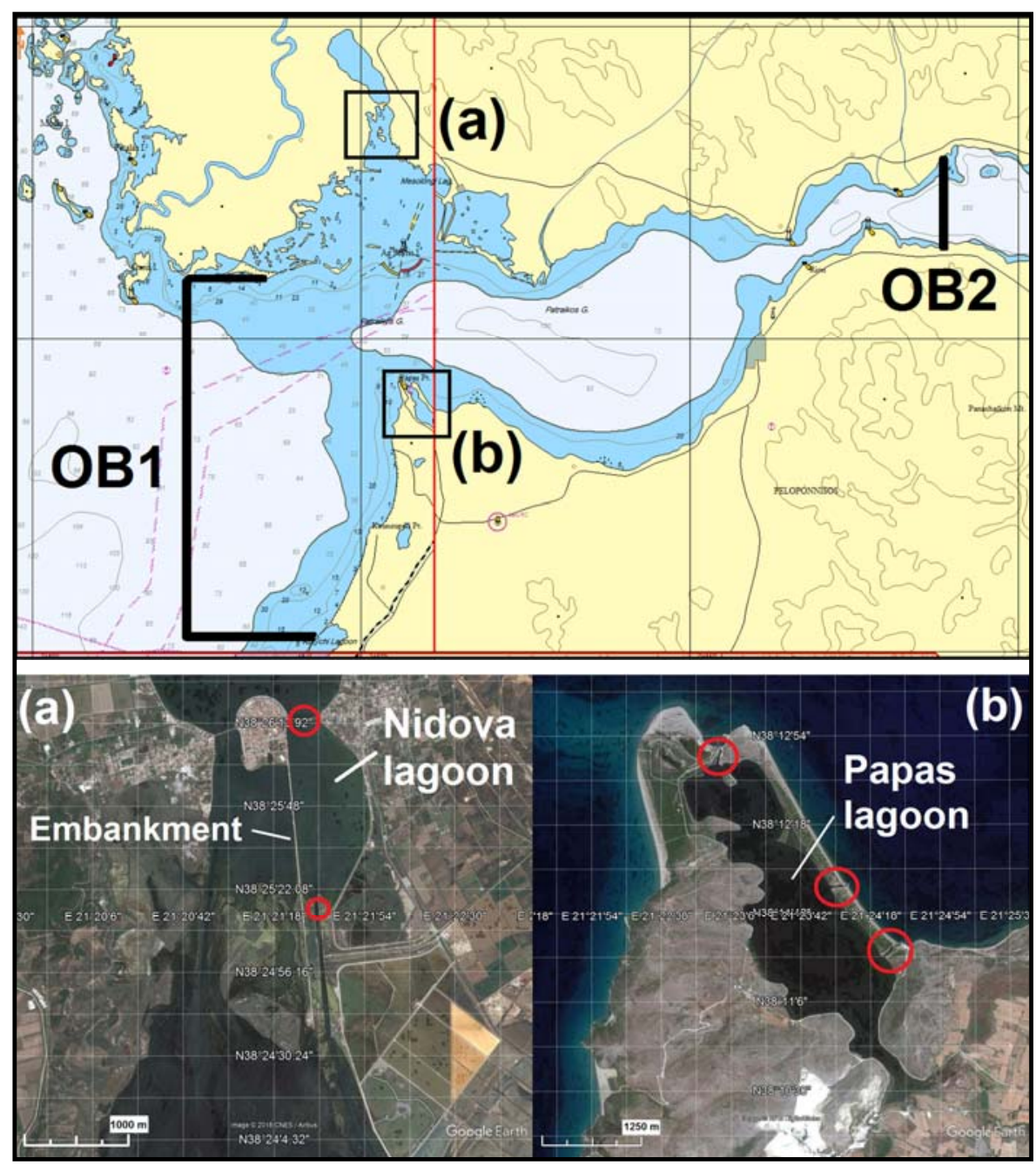

Figure 1. Upper panel: General map of the wider area of the Gulf of Patras in western Greece (adapted from MIKE C-MAP, 2018, [15]). The open boundaries have been marked with black lines. Land area is given in yellow; sea area is given in blue and white (blue for depths $<50 \mathrm{~m}$ and white for depths $>50 \mathrm{~m}$ ). Detail of the areas of interest is given in the lower panel for (a) the Nidova lagoon (Google Earth, 12-08-2017) and (b) the Papas lagoon (Google Earth, 15-07-2016) [16]. The locations of tidal inlets are denoted with red circles.

The lagoon is subject to extensive fish exploitation and aquaculture. It is naturally eutrophic, with no anthropogenic influences on the waterfront. Within the last 35 years, nine dystrophic crises have been reported, followed by mass fish mortality and benthic fauna; these occurred during the summer months of the years 1979, 1984, 1987, 1996, 1997 [17], 2004, 2010, and 2012 [18]. The dystrophic crises have been related to the decomposition of large beds of macro algae [14].

Both lagoons are protected by the Ramsar Convention, and the Nidova lagoon is also included in the Natura 2000 network. The proper management of the lagoons, which is of primary importance to local fishermen, includes plans for dredging operations, creation of inlets, or other infrastructure works in the area, with the aim of improving the hydrodynamic circulation and water renewal of these ecosystems. 


\subsection{The Hydrodynamic Code and the Advection-Diffusion Code}

The simulations presented herein have been performed using the commercially available CFD (Computational Fluid Dynamics) code MIKE21 and MIKE3 Flow Model FM (where FM stands for flexible mesh). The MIKE3 Flow Model FM has been used for three-dimensional flow simulation in the Messolonghi-Aetoliko lagoon. It is a modeling system developed by the Danish Hydraulic Institute (DHI), based on a finite volume and an unstructured mesh approach. The hydrodynamic module (HD) extracts numerical solutions from the three-dimensional continuity, momentum, temperature, salinity, and density equations. The momentum equations are used in the incompressible, Reynolds-averaged form of the Navier-Stokes equation (RANS), invoking the Boussinesq assumption and the hypothesis of hydrostatic pressure in the vertical. The turbulence closure is achieved using the Smagorinsky formulation for diffusion in the horizontal and the standard $k-\varepsilon$ model in the vertical direction. To account for the Coriolis force, an f-plane has been used. The free surface is taken into account using a sigma-coordinate transformation. The spatial discretization of the primitive equations is performed using a cell-centered finite volume method. In the horizontal plane an unstructured grid is used, while in the vertical direction the discretization is structured. The elements are prisms or bricks whose horizontal faces are triangles or quadrilateral elements, respectively. A Riemann solver is used for computation of the convective fluxes in vertical interfaces, which makes it possible to handle discontinuous solutions. For convective fluxes in horizontal interfaces, two schemes are available: a low order (based on upwinding) and a high order. The low-order scheme requires considerable less time than the high-order scheme. Use is made of the high-order scheme for the accurate simulation of the advection-diffusion simulations (see Section 2). For the time integration a semi-implicit approach is used, where the horizontal terms are treated explicitly and the vertical terms implicitly [19].

The MIKE 21 FM (HD) model has been used for simulations of the tidal propagation in the Gulf of Patras, thus providing the boundary conditions both at the entrance of the Messolonghi-Aetoliko lagoon (in the NW part of the Gulf) and at the tidal inlets of the Papas lagoon (in the SW part of the Gulf). The model simulates unsteady two-dimensional flow in one layer of vertically homogeneous fluid, by having the equations for the conservation of mass and momentum integrated over the vertical [20]. We note that the entrances of both the Papas lagoon and the Messolonghi lagoon are at a safe distance from the Rio-Antirio straits, where the presence of stratification influences local hydrodynamics [21]. Thus, the depth-averaged simulations produce adequate boundary conditions for the three-dimensional simulations of flow in both lagoons.

Finally, the advection and diffusion of the conservative tracer, applied in the Nidova and Papas lagoons, is simulated utilizing the CFD code MIKE 3 FM Transport Module (TR). This modeling system simulates the spreading and fate of dissolved or suspended substances in an aquatic environment under the influence of the fluid transport and the associated diffusion processes. The hydrodynamic basis for the Transport Module (TR) is calculated with the Hydrodynamic Module (HD) [22].

\subsection{Computational Domain and Grid}

Due to a lack of free surface time series measurements at the entrance of the tidal inlets of the Nidova and the Papas lagoons, which would have been adequate data as boundary conditions for flow simulations, the only alternative is the computation of such data. The only locations that are suitable for boundaries of numerical simulations and where, at the same time, the harmonic constituents of the tide are available, are both ends of the Gulf of Patras, one of which is close to the southern opening of the Messolonghi lagoon and the tidal inlets of the Papas lagoon [23]. It would have been numerically inefficient to perform fully three-dimensional simulations in a domain comprising of an area as large and deep as the Gulf of Patras (135 m maximum depth) together with the lagoonal systems, which includes extensive areas with depth less than $0.5 \mathrm{~m}$, to focus on a small section of the entire Messolonghi-Aetoliko lagoon, namely the Nidova lagoon. Thus, it was decided to resort to two-dimensional, depth-averaged simulations in a domain similar to the one used by [24] covering the entire area of the Gulf of Patras to extract boundary conditions for the three-dimensional simulations 
in the Messolonghi-Aetoliko lagoon. Such two-dimensional simulations are adequate, in terms of tidal propagation, even in summer conditions when thermal stratification is set in the lagoon ecosystems.

\subsubsection{The Nidova Lagoon}

The numerical domain for the three-dimensional simulations covers the entire Messolonghi-Aetoliko lagoonal system and a small part of the adjacent open waters of the northwestern part of the Gulf of Patras (i.e., the coastal waters in front of Messolonghi lagoon). This domain was discretized using a numerical grid consisting of a three-zone triangular mesh in the horizontal (Figure 2). In the first zone, covering the northwestern part of the gulf of Patras, the characteristic length is up to $400 \mathrm{~m}$ offshore. In the second zone, the characteristic length is $200 \mathrm{~m}$ and covers the greater area of the Messolonghi-Aetoliko lagoon complex, upstream and downstream of the area of interest, and in the third zone the length dimension varies from 20 to $50 \mathrm{~m}$ and covers the transitional part between the Messolonghi and Aetoliko lagoons, where the area of the Nidova lagoon is embedded.

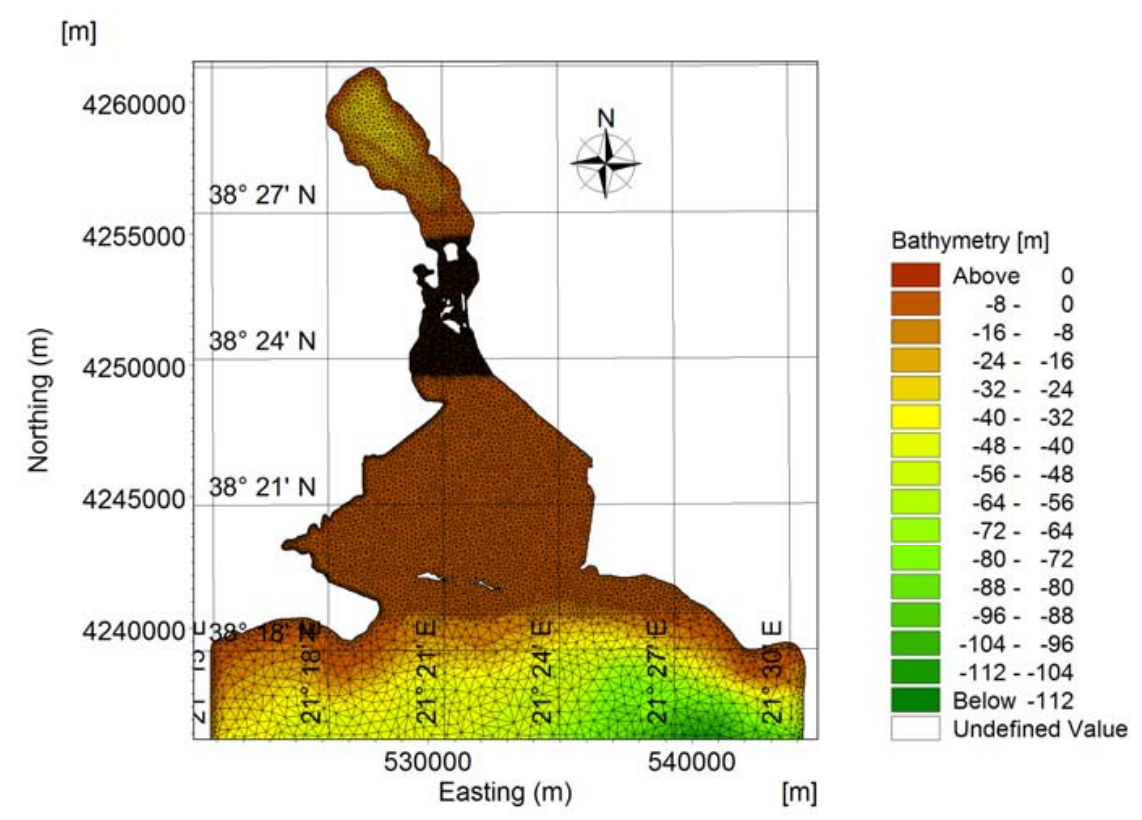

Figure 2. Bathymetric map of the Messolonghi, Aetoliko, and Nidova lagoons, with isobaths shown every $8 \mathrm{~m}$. Superimposed is the unstructured triangular mesh. The coordinate system refers to UTM-34. In the middle of the domain a finer mesh covers the wider area of the Nidova lagoon.

The goal of the present study is to compare how the residence time of semi-enclosed water bodies (i.e., lagoons) depends upon the details of their geometry. Since the evaluation of residence times is based on simulations of numerical tracers' transport, it was found necessary, in order to increase the accuracy, to create a third (even smaller) domain (Figure 3), consisting of the entire Nidova lagoon, the Aetoliko lagoon, and part of the surrounding Messolonghi lagoon area. It is within this truncated domain that the Nidova waters are estimated to remain when exchanged with adjacent waters of the Messolonghi and Aetoliko lagoons under tidal forcing, at least for the time span of interest. Again, the free-surface-time-series boundary conditions for this truncated domain are to be obtained from flow simulations in the immediately larger domain (Figure 2). In the truncated domain, the numerical grid consists of 10 equidistant layers in the vertical, and a horizontally varied mesh lying between 10 and $20 \mathrm{~m}$. This domain proved adequate for simulations covering at least 40 days, which, as verified a posteriori, greatly exceeds the water residence time for the Nidova lagoon.

Finally, to produce a grid on which the numerical simulations would require a reasonable amount of computer time, it was found necessary to merge in one opening all the openings of the series 
of arches supporting the stone bridge located at the junction of the Nidova and Aetoliko lagoons. The reason for this approximation is that the span of the arches is barely a few meters, so discretization of all the arches would require a mesh of characteristic length on the order of $30 \mathrm{~cm}$ or so, which is not practical. This practice gave rise to the discretization depicted in Figures 2 and 3.

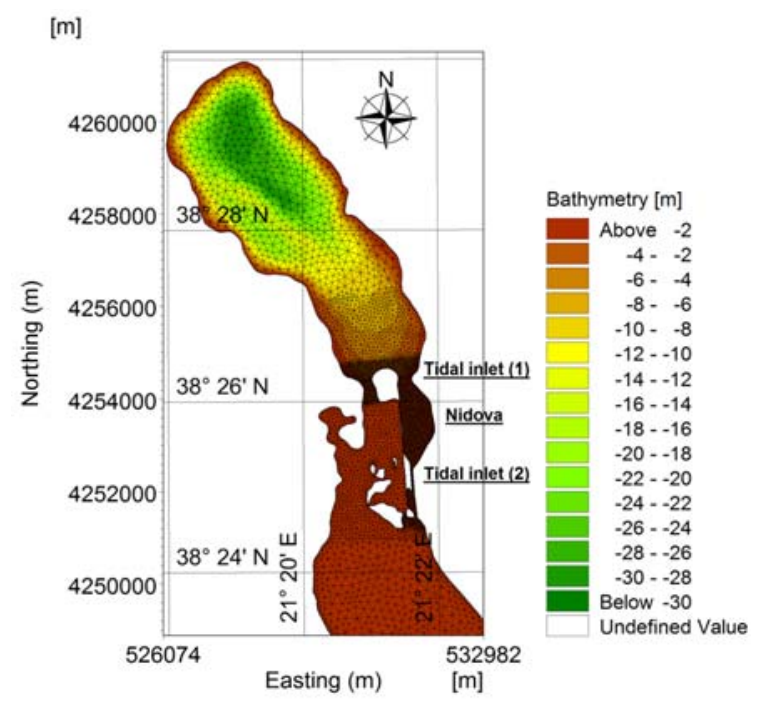

Figure 3. Truncated domain for the wider area of the Nidova lagoon, covering the Aetoliko lagoon and part of the Messolonghi lagoon.

\subsubsection{The Papas Lagoon}

Concerning the Papas lagoon, a truncated computational domain was formed covering the entire lagoon and the adjacent open waters of the southwestern part of Gulf of Patras, consisting of three zones in the horizontal (Figure 4).

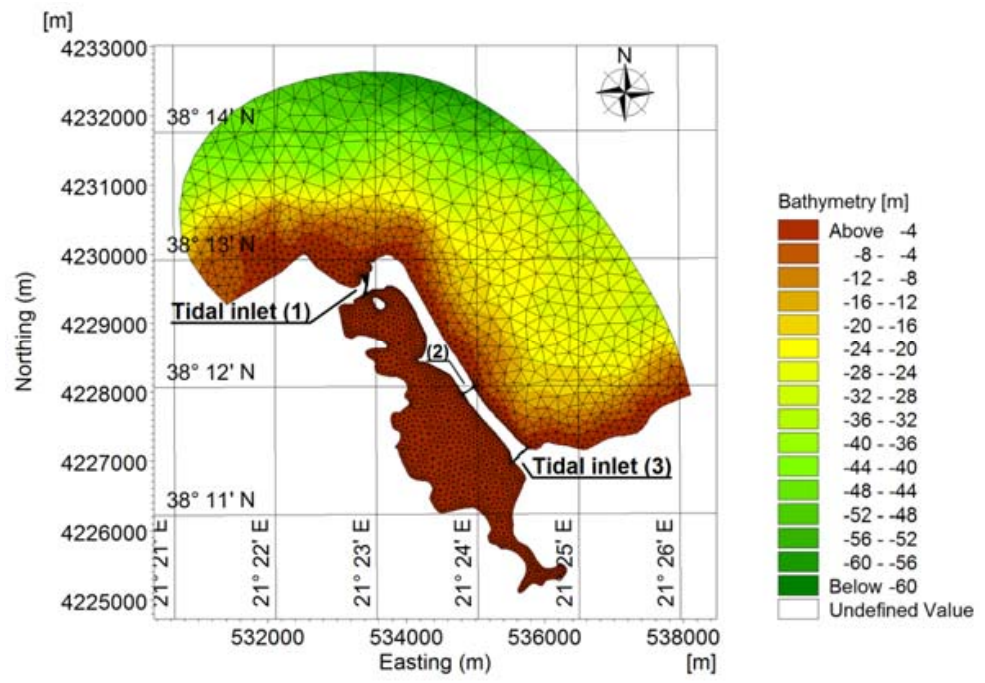

Figure 4. Truncated domain for the wider area of the Papas lagoon, covering part of the Gulf of Patras.

In the first zone, grid triangles have a characteristic length of up to $300 \mathrm{~m}$ offshore, and cover the southwestern part of the gulf of Patras, which is included in the simulation domain. In the second zone, the characteristic length varies from 20 to $100 \mathrm{~m}$ and covers the greater area of the Papas lagoon, which is the area of main interest and, finally, in the third zone, the cells' dimension varies from 5 to $20 \mathrm{~m}$ and covers the tidal inlets of the lagoon as well as the transitional part between the 
open gulf's waters and the lagoon. This truncated domain is designed so that its periphery is very nearly an equitidal line, and, as in the case of Nidova, was made large enough so that waters initially inside the Papas lagoon and later exchanged with Gulf of Patras waters will remain inside this domain during the whole length of the simulations, as verified by the numerical tracer experiments. The grid consists of 10 equidistant layers in the vertical.

\subsection{Boundary and Initial Conditions}

In all cases considered herein, the coastline has been defined as an impermeable, zero normal velocity boundary, while the bottom is a no-slip (via wall functions), impermeable boundary. For the first domain where the Nidova lagoon is located, the bottom roughness was set equal to $0.01 \mathrm{~m}$ and care was taken to ensure that the geometry of the bottom cell was compatible with the requirement of fully rough flow, assuming the minimum flow depth to be $0.4 \mathrm{~m}$. In the transitional part, i.e., in the interior of Messolonghi lagoon, a higher bottom roughness was considered in order to represent the vegetated bottom of the shallow lagoon. At the southern end of the computational domain lies the Gulf of Patras: it is from this boundary that the tide enters the lagoons, namely OB1 (Figure 1). To formulate an elevation time series for the location of this open boundary, results from the two-dimensional simulations of the Gulf of Patras were used in the simulations that follow. For the secondary truncated domain (Figure 3), used for the experiments with the tracer, tidal boundary conditions were extracted from the previously conducted simulations of the intermediate domain (Figure 2).

Concerning the Papas lagoon, tidal elevation time series that resulted from the two-dimensional simulations of the Gulf of Patras were used as open boundary conditions in the simulations that follow (Figure 4).

Initial conditions were needed in all four regions: (a) the Aetoliko lagoon at the northern of the domain, (b) the Messolonghi lagoon in the central part, (c) the opening (OB1) at the northeastern part of the Gulf, and (d) the Papas lagoon. Mean temperature and salinity profiles were imposed as initial conditions throughout the Aetoliko basin, based on the field measurements at four stations covering the longitudinal axis of the lagoon in a NW-SE direction, measured in July 2010 [25], since these measurements showed little horizontal variation. Since this dataset included no measurements in the Messolonghi lagoon, field measurements performed by [26] in the same summer period, i.e., July 2006, were used. Finally, the required profiles for the Gulf of Patras were taken as in [21].

Concerning the Papas lagoon, the simulations were performed considering barotropic flow in the basin even for the summer months, when the Gulf's waters (outside the Papas lagoon) were found to be stratified [27]. This seems justified because in the shallow waters of the Gulf, within the domain chosen, previous simulations show that the stratification is destroyed and the waters become nearly isothermal and these waters are of constant salinity. Further, according to measurements of [28], stratification does not seem to be important in the lagoon during the summer months. Therefore, the flow, both into the lagoon and in the near vicinity outside it, can be taken as homogeneous.

\subsection{The Tracer}

In this section we present the method we applied to estimate the residence time of the Nidova and Papas lagoonal ecosystems. Various transport time scales have been used in the literature to quantify the renewal of waters in natural systems (e.g., [29]). The present work has been stimulated by research in coastal lagoons that suffer from recurring dystrophic crises, the inception of which has been observed to occur locally before spreading to the entire lagoon [18]. Therefore, it is desirable to aim at calculating a time scale characterizing the local transport rate rather than an integral time scale characterizing the overall renewal of the entire lagoon. For the Papas lagoon, the latter has been carefully calculated in the form of flushing time by [14], who based their calculations on water quality measurements in the lagoon. We note that even though they call their time scale a residence time, we have referred to it as a flushing time since herein we use the definition of [29] for flushing time as an integral scale, and retain the local character they give to the term residence time. 
More precisely, for the purposes of the calculation, we define as residence time the time needed for the concentration of a conservative, passive tracer to fall to $1 / \mathrm{e}(\sim 37 \%)$ of its initial value (see for example [30,31]). By defining the initial concentration of the conservative numerical tracer to be equal to 1 inside and 0 outside the lagoon, we are thus able to calculate the residence time at each point inside the lagoon by following the evolution of the concentration of the tracer as determined by the advection-diffusion equation. This information should be useful in the analysis of the very complex problem of the inception of the recurring dystrophic crises that plague especially the Papas lagoon. We note, however, that the e-folding value is a mere convention and that in different applications the use of different cutoffs may be required. This is especially true for research concerning the causes of the dystrophic crises, a topic not well understood at this time.

\section{Results and Discussion}

\subsection{Hydrodynamic Characteristics of the Lagoon Ecosystems}

Both the Nidova and the Papas lagoon communicate with the Gulf of Patras: the former is situated in the northwest, whereas the latter is in the southwest of the Gulf (Figure 1), and are therefore subject to similar tidal forcing, in terms of amplitude, because the distance of both locations from the Rio-Antirio Straits, where the semidiurnal tide entering the Gulf of Patras from the Ionian Sea undergoes the reflection [24], is nearly the same. In the following summary of the salient features of the hydrodynamic forcing of the lagoons, we confine our attention to the purely tidal flow, ignoring wind-induced effects, since this is the most severe situation that arises, in terms of water renewal, in both lagoons.

An instance of the velocity field induced by flood tide in the Messolonghi-Aetoliko lagoonal system is depicted in Figure 5, where it can be observed that surface velocities range between 5 and $12 \mathrm{~cm} / \mathrm{s}$, except in locations where the depth is very shallow. The high velocities are especially pronounced at the sand bars, i.e., in sites where tidal inlets are formed, at the entrance of the Messolonghi lagoon (from the Gulf of Patras), and are crucial for fish migration into the lagoon ecosystem.

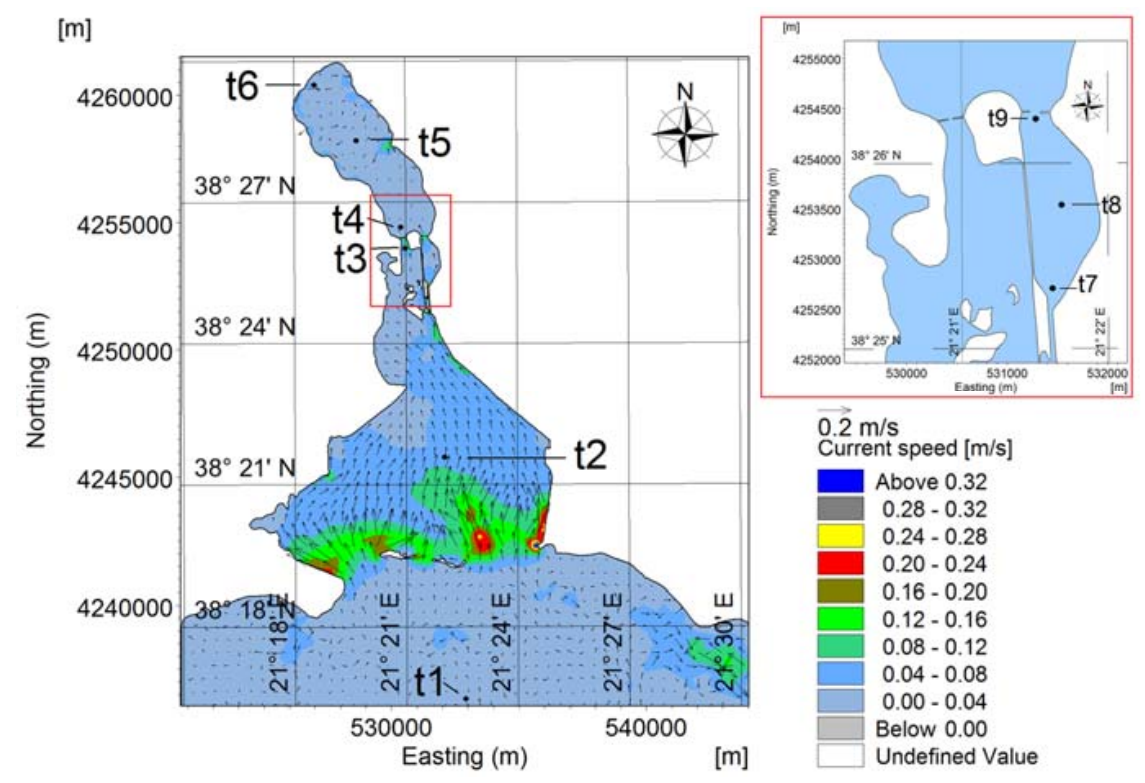

Figure 5. The surface flow field during flood tide into the Messolonghi-Aetoliko lagoonal complex. At the right upper corner, detail of the wider area of Nidova lagoon is shown, and numerical stations $\mathrm{t}$, $\mathrm{t} 8$, and $\mathrm{t} 9$ are marked.

The very shallow tidal flow in the Messolonghi and Nidova lagoons is controlled by high bottom friction. This is documented in Figure 6, where it is shown that, as we proceed from the Gulf of Patras towards the Aetoliko lagoon through the Messolonghi lagoon, there is a decrease in the amplitude of 
the tide and a delay. The latter becomes manifest as a phase difference between the time series at the entrance of the Messolonghi lagoon (which is also the entrance of the underwater trench that leads to the Southern entrance of Nidova) and at the stone bridges, which delineate the northern end of the Messolonghi lagoon but also of the Nidova lagoon (with the interpolation of the Aetoliko island). Thus, the Gulf of Patras tide reaches the northern end of the Nidova lagoon via the Aetoliko lagoon, the surface of which undergoes oscillations in unison, because of its relatively large depth (from $12 \mathrm{~m}$ in the southern part up to 30-35 $\mathrm{m}$ in the northern part). This differential path the tide of the Gulf of Patras has to take in order to reach the two ends of the Nidova lagoon results in the development of a differential amplitude and a phase lag and therefore a pressure gradient along the Nidova lagoon (Figure 7). This seems to be the key factor that causes the Nidova lagoon to function as a flow-through lagoon, with a concomitantly short time of water renewal, as we shall see in the following.

This analysis was tested by performing a simulation in which we closed the tidal inlet that connects the Nidova and Aetoliko lagoons, so as to block the flushing phenomenon. The result was, anticipating Section 3.2 below, that the residence time for this blocked Nidova lagoon increased to 20 days, as compared to the less than three days when flushing is allowed to occur.

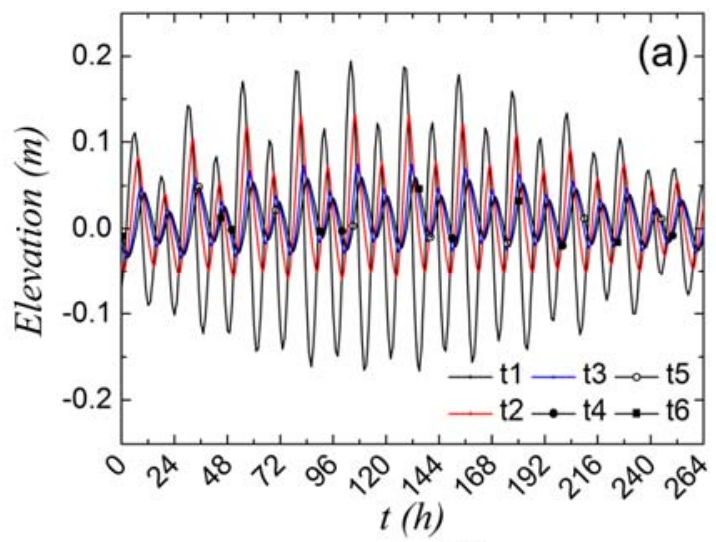

$t$ (h)

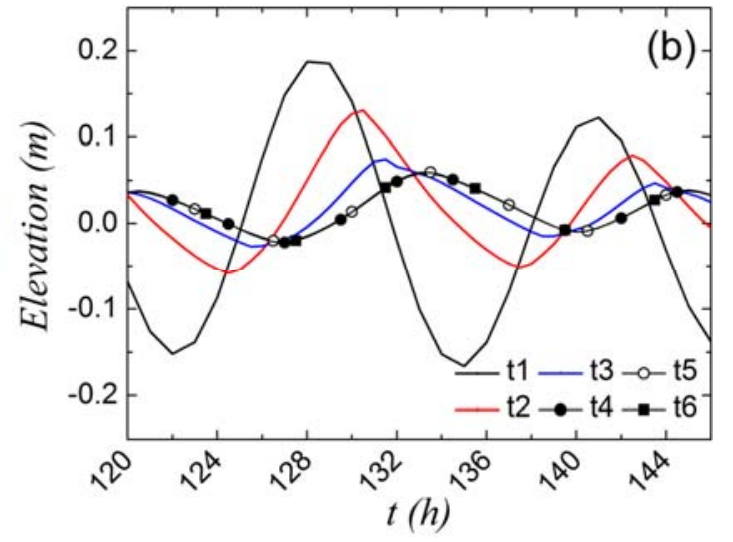

(c)

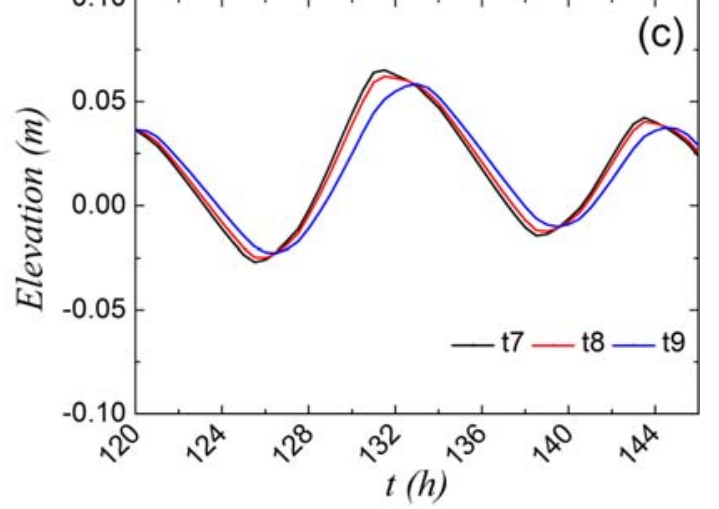

Figure 6. (a) Time series of tidal elevation at selected points along the longitudinal axis of the Messolonghi-Aetoliko lagoons, covering a simulation period from neap to spring tides, $(\mathbf{b}, \mathbf{c})$ detail where tidal amplitude decrease and phase lag are revealed during the propagation of the tide in the lagoonal system. The sites of the points are marked in Figure 5. 


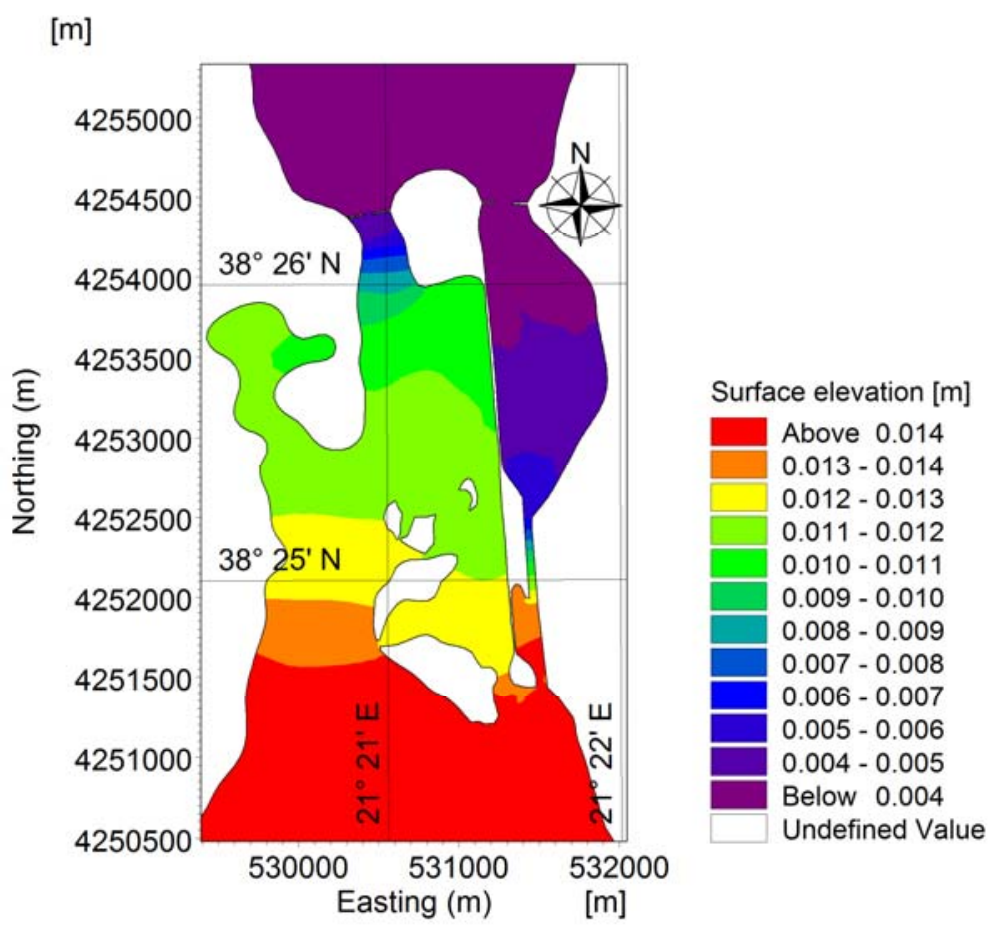

Figure 7. Sea surface formation during the tidal propagation in the wider area of Nidova lagoon.

If we were to confine our attention to its geometry alone, we would have to classify Nidova, with its two tidal inlets as a restricted lagoon and would have expected, accordingly, its water renewal to be rather slow. The fact that the two inlets of the lagoon are situated on opposite sides of its long axis does not by itself dictate the functioning of the lagoon as a flow-through system, because, as we shall see, nearly the same geometrical setting exists for the Papas lagoon, but there the hydrodynamics impose a radically different forcing. This fact has not been reported in the literature before, and therefore needs closer examination as to the exact circumstances in which it occurs. It seems, however, to be a variation of the famous, in the history of science, precedent of the quasi-periodic currents created by the differential arrival at the Strait of Euripus (between mainland Greece and the island of Evvoia (or Euboea) of the tide moving around Evvoia [32,33]. These currents have been famous since ancient times because they were associated with the name of Aristotle, who, living his last years in Evvoia, became fascinated with them, though he only had partial success in explaining the phenomenon [34,35].

The specific values for the tidal circulation in the Nidova lagoon are as follows. The incoming water, i.e., the exchange flowrate (Figure 8), was computed to range between $8 \mathrm{~m}^{3} / \mathrm{s}$ (neap tides) and $24 \mathrm{~m}^{3} / \mathrm{s}$ (spring tide), with an intermediate value of $\sim 11 \mathrm{~m}^{3} / \mathrm{s}$ (e.g., mean tidal range). Maximum flow velocities of tidal currents of $0.5 \mathrm{~m} / \mathrm{s}$ and $0.4 \mathrm{~m} / \mathrm{s}$ occur in the dredged trench during the flood and ebb phases of the tidal action, respectively. Water velocities were found to diminish rapidly in the submerged open channel, with values of $0.20-0.30 \mathrm{~m} / \mathrm{s}$ at the free surface, while near the bottom these values were decreased to $0.05-0.1 \mathrm{~m} / \mathrm{s}$. In contrast, at the opposite side of the lagoon, i.e., in the neighborhood of the arc stone bridges, a water flow velocity of approximately $0.2 \mathrm{~m} / \mathrm{s}$ developed. To summarize, the numerical predictions show that the Nidova lagoon is being flushed through the south dredged trench, transferring tidal waters from the greater Messolonghi lagoon to the deeper Aetoliko lagoon in the north and back to the Gulf of Patras. 


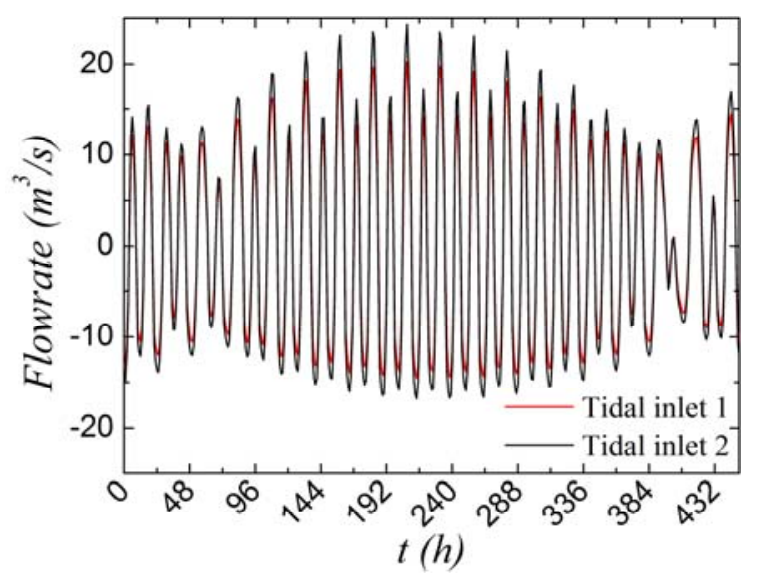

Figure 8. The hydraulic exchange flowrate between the Nidova lagoon and the surrounding waters (i.e., Aetoliko lagoon - tidal inlet 1, Messolonghi lagoon - tidal inlet 2).

In contrast to the Nidova lagoon, the Papas lagoon is subject to a straightforward tidal forcing. It has three tidal inlets: two in the eastern side and one in the northern side of the lagoon, and all of them are exposed immediately to the semidiurnal tide of the Gulf of Patras. The distances between them are small so that both the amplitude and the phase of the tide is practically the same in all three. An instance of the velocity field induced by flood tide in the lagoonal system is depicted in Figure 9, where it can be observed that surface velocities range between 0.5 and $20 \mathrm{~cm} / \mathrm{s}$, except in locations where the flow is strongly affected by the presence of the inlets. The high velocities are especially pronounced at the three inlets and in front of these, since the tidal currents through the narrow inlets flowing into the wide lagoon form a tidal jet, often called a mushroom jet, as it generates a vortex pair. When the tide reverses (ebb flow), the pattern of the flow resembles a radial flow to a sink [36]. The hydraulic exchange flowrate between the lagoon and the Gulf's open waters, via the three tidal inlets, is given in Figure 10. It can be seen that the exchange flowrate for the three inlets ranges between $4-6 \mathrm{~m} 3 / \mathrm{s}$ (neap tides) and 7-15 m3/s (spring tide), with an intermediate value of $5-10 \mathrm{~m} 3 / \mathrm{s}$ (e.g., mean tidal range).

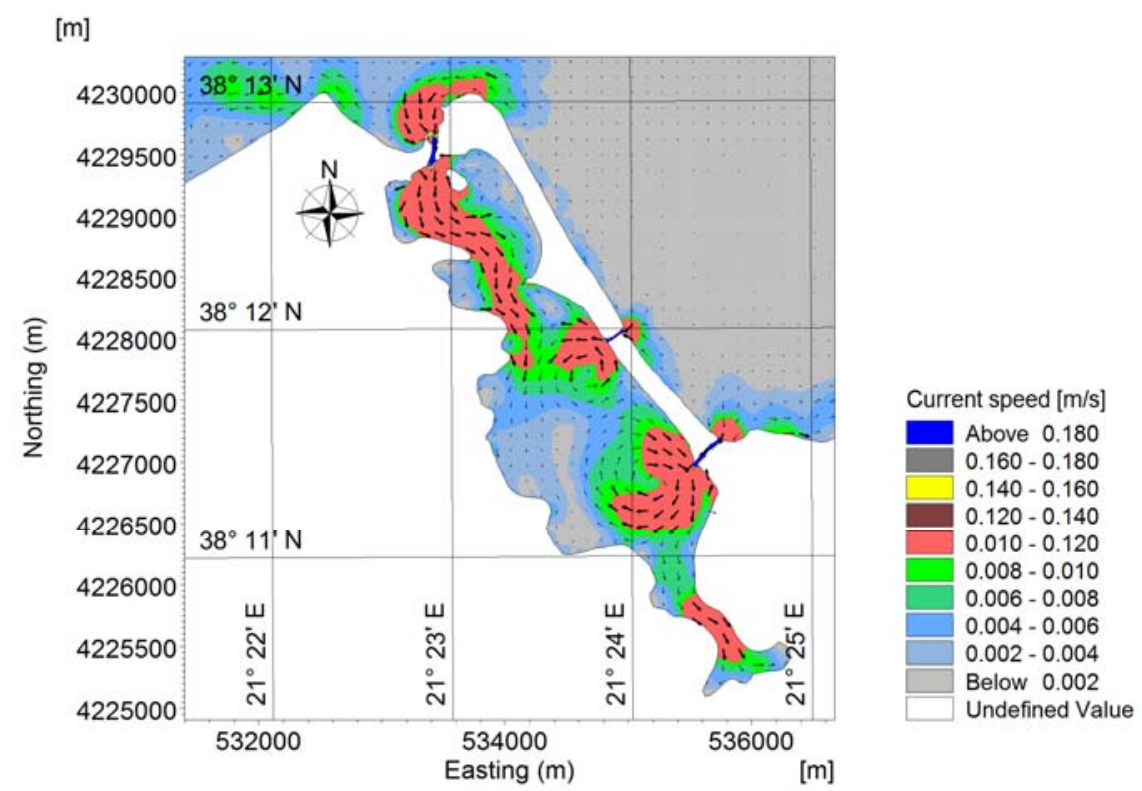

Figure 9. Cyclonic and anticyclonic gyres that form in the vicinity of tidal inlets in Papas lagoon during the flood tide. 


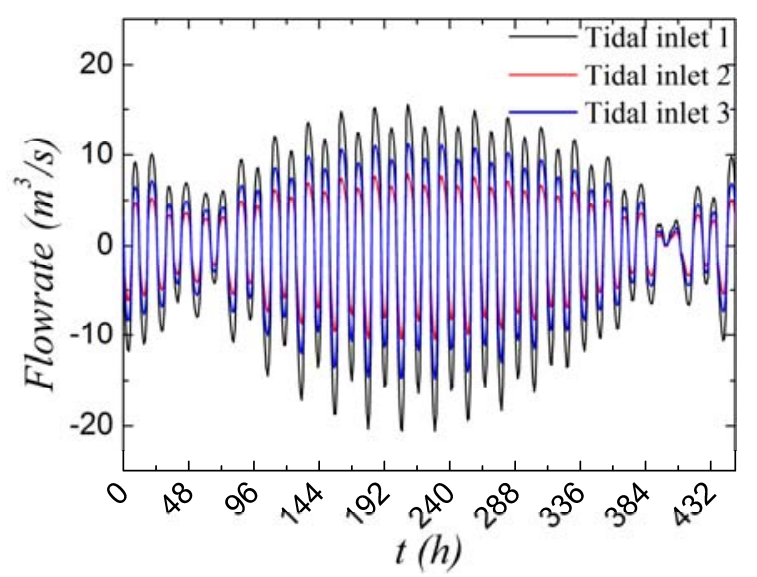

Figure 10. The hydraulic exchange flowrate between the Papas lagoon and the Gulf of Patras.

\subsection{Residence Time of the Lagoons}

\subsubsection{The Nidova Lagoon}

Based on the above description of the tidal hydrodynamics of the Nidova basin, it is clear that the renewal mechanism of its waters differs substantially from the mechanism based on the mere introduction of a volume of water equal to the tidal prism at the first half of the tidal cycle, recirculation and mixing of that volume within the lagoon, and subsequent exit of an almost equal amount in the second half of the tidal cycle. This is because the water introduced from the southern tidal inlet moves northwards and in part exits from the northern inlet into the Aetoliko lagoon, where it mixes with the Aetoliko lagoon waters before proceeding to the second half of the cycle.

To produce a value for the residence time scale, the procedure described in Section 2.5 was followed. The result is summarized in Figure 11, from which it follows that renewal is achieved in less than three days.

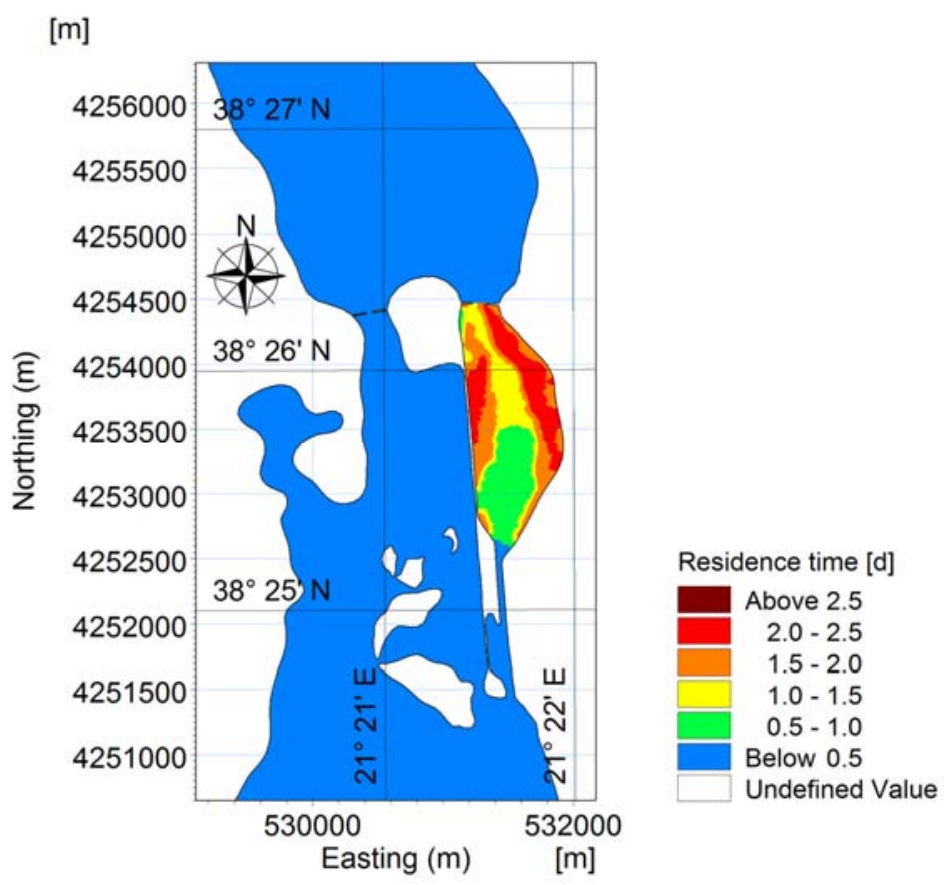

Figure 11. Spatial distribution of the residence time of the conservative tracer for the Nidova lagoon. Values below 0.5 refer to 0 initial concentration. 
It should be stressed again that this specific value depends strongly on the definition of the threshold under which the tracer's value is considered small, so that the timescale value should be used with great care and in conjunction with the desired application. A further note of caution is in order for the specific site we are analyzing. From the above description, it follows that waters that exit the Nidova lagoon mix with the Aetoliko lagoon waters before re-entering in Nidova. Thus, the time scale determined is meaningful as a short-term scale. This is because we base our calculation on the decrease of a substance introduced once into the Nidova lagoon. If, however, substances such as agricultural fertilizers are being introduced intermittently into the Aetoliko lagoon, the result might be a more or less well mixed water volume of a substantial contaminant that would be recirculated within the Aetoliko-Nidova-Messolonghi lagoonal system within each tidal cycle. This might be the reason why, in spite of its impressively low residence time, recurring thick algae blooms have been observed to develop during the last few years in the Nidova lagoon.

The note of caution concerning the definition of the residence time using the standard e-folding value becomes concrete in the following simulated scenario. The effect on residence time of removing the embankment separating the Nidova lagoon from the Messolonghi lagoon was examined numerically. From a purely hydrodynamic point of view, removing the embankment enhanced the circulation, making possible the development of a gyre encompassing both the Messolonghi and the Nidova lagoons (Figure 12). The residence time, however, was not significantly changed, still remaining below three days.

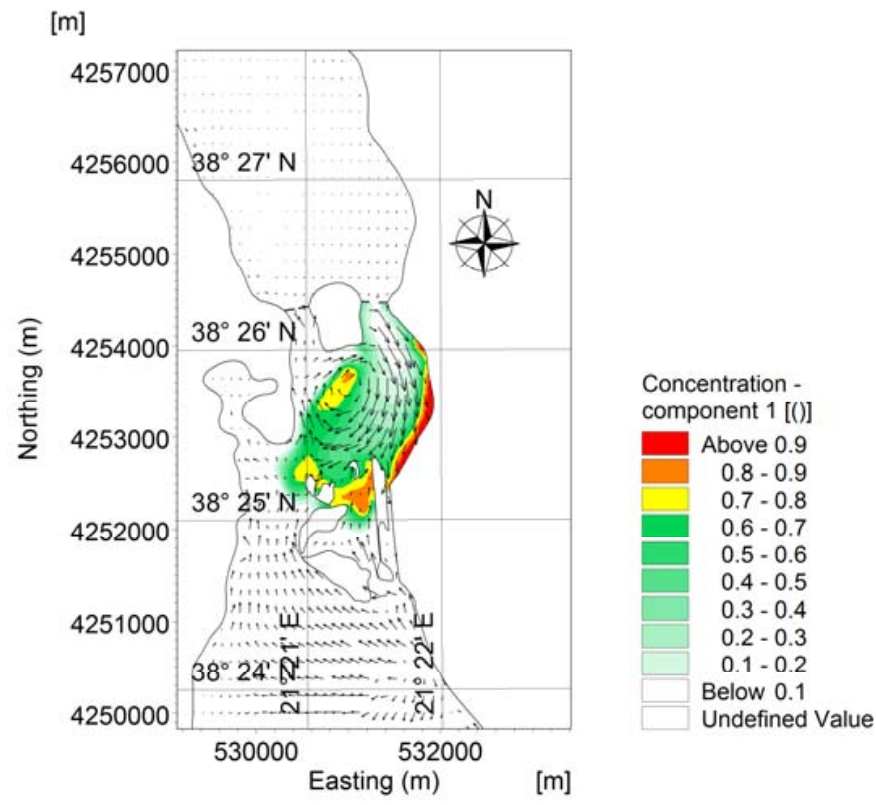

Figure 12. Spatial distribution of the concentration of the conservative tracer for the Nidova lagoon, after the embankment's removal, under the development of an anti-cyclonic gyre.

The above analysis rests on a very important condition that should be underlined. The dredged trench, connecting the southern end of the Nidova lagoon with the Messolonghi lagoon, should remain clear of transported material so as to ensure that the Gulf of Patras-Messolonghi-Nidova-Aetoliko system remains a flow-through system.

\subsubsection{The Papas Lagoon}

The numerical results showed that the residence time in the water body exhibits a strong spatial variation. In the region located in front of the inlets, rapid mixing occurs and these areas have the shortest residence time ( $\sim 5$ days). The southern, somewhat isolated shallow region and also the deeper central-western region, which is relatively far from the inlets, seems to remain at a near 
stagnation state for significant time intervals, having a residence time of more than 40 days (Figure 13). The hydrodynamic gyres due to tidal action cause a conservative tracer to be trapped between the two openings in the eastern side of the lagoon. In the middle area of the eastern openings, a rather unexpectedly high residence time appears. This area seems to be at a near stagnation state, having a residence time of approximately 25-30 days. It is worth noting that it is in this area, i.e., in the vicinity of tidal inlets, that the dystrophic crisis occurred in June 2012 [18], showing that the high residence time in this area is not incompatible with the local initiation of dystrophic phenomena.

Finally, it is worth noting that the northern tidal inlet and the lower of the two eastern inlets are geometrically in nearly opposite positions. This lagoon, however, does not function as a flow-through lagoon because the tidal hydrodynamics do not favor it. In other words, the tide arrives simultaneously at all the inlets, with no substantial difference in amplitude. This is the reason why the opening of the middle inlet in 1992 [18] made only a limited contribution to the renewal of the waters of the Papas lagoon.

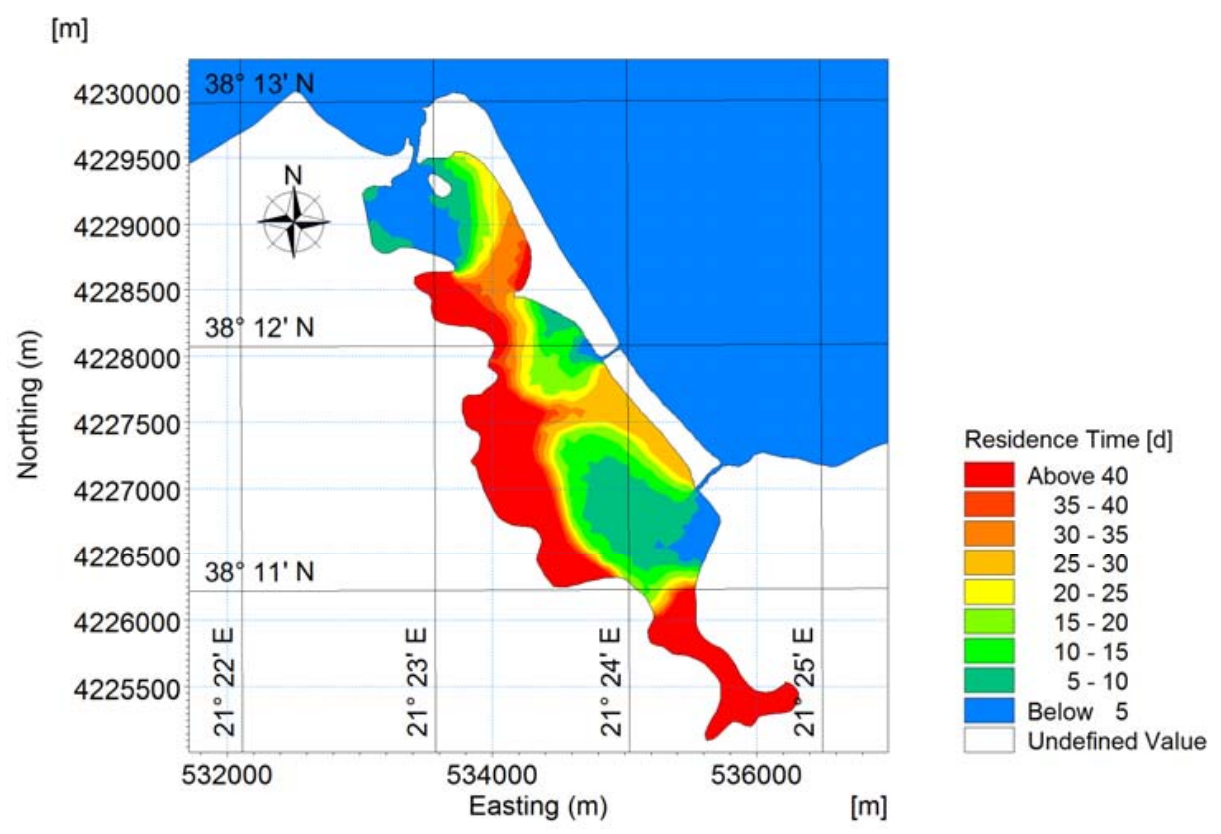

Figure 13. Spatial distribution of the residence time of the passive tracer for the Papas lagoon. Values below 5 outside the lagoon refer to 0 initial concentration.

\section{Conclusions}

Restricted lagoons suffer from long residence times, which result because of the limited tidal hydraulic exchange between the lagoon and the adjacent open water body (the ocean). The present study documented, however, that this state is not solely a result of the geometry of the lagoon, but also of the intricacies of the tidal hydrodynamics, making credible the term "hydrodynamic geometry". This term is meant to signify that if the geometry is in the right relation with the tidal forcing applied at different tidal inlets of the lagoon, the result may be the creation of a flow-through system, which flushes the lagoon waters considerably more efficiently that the slow process of tidal prism exchange and mixing in successive tidal cycles. An example of the former is the Nidova lagoon, and the Papas lagoon of the latter: both are situated in Western Greece and forced by the same tide of the Gulf of Patras. The creation of strong currents because of the differential arrival of the tide at different locations is not as exotic as it might seem since it has also been known to happen in open waters, as in the well-known Evripos straits. This advantage, in terms of flushing rate, should therefore be taken into account whenever possible when deciding the opening of an additional tidal inlet in a lagoon in order to enhance its flushing rate. 
Acknowledgments: Useful discussions with Professors Yannis Cladas, of the Technological Educational Institute of Western Greece, and Constantin Koutsikopoulos, of the University of Patras, are gratefully acknowledged. Publication costs were provided by the Hydraulic Engineering Laboratory, Department of Civil Engineering, University of Patras.

Author Contributions: Nikolaos Th. Fourniotis and Georgios M. Horsch conceived and designed the numerical experiments, carried out the analysis and interpretation of the results, and wrote the paper; Nikolaos Th. Fourniotis and Georgios A. Leftheriotis performed the numerical simulations and analyzed the numerical results.

Conflicts of Interest: The authors declare no conflict of interest.

\section{References}

1. Colombo, G. Lagoons. In The Coastline; Barnes, R.S.K., Ed.; John Wiley and Sons: New York, NY, USA, 1977; pp. 63-81.

2. Tsihrintzis, V.A.; Sylaios, G.K.; Sidiropoulou, M.; Koutrakis, E.T. Hydrodynamic modeling and management alternatives in a Mediterranean, fishery exploited, coastal lagoon. Aquac. Eng. 2007, 36, 310-324. [CrossRef]

3. Koutsikopoulos, C.; Dimitriou, E.; Rogdakis, Y.; Katselis, G.; Pagoni, S.; Kentrou, A.; Koutrakis, E.; Cladas, Y.; Economidis, P.S. A typology of the Hellenic lagoons based on physical and socio-economic aspects on their fisheries characteristics. In Proceedings of the International Conference on Lagoons and Coastal Wetlands in the Global Change Context, Impacts and Management Issues, Venice, Italy, 26-28 April 2004; pp. $26-28$.

4. Cataudella, S.; Crosetti, D.; Massa, F. Mediterranean Coastal Lagoons: Sustainable Management and Interactions among Aquaculture, Capture Fisheries and the Environment; Food and Agriculture Organization of the United Nations (FAO) Studies and Reviews No. 95; FAO: Rome, Italy, 2015; p. 278.

5. Dimitriou, E.; Economidis, P.S.; Athanasopoulos, T.; Kapareliotis, A.; Katselis, G.; Koutrakis, E.; Koutsikopoulos, K.; Liourdi, M.; Manios, V.; Roussi, A.; et al. Study of the organization and function of fishery use in lagoons. PESCA, ICHTHIKA S.A., Department of Fish-farming and Inland Waters, Hellenic Ministry of Agriculture, 2001; Unpublished work.

6. Corsi, F.; Ardizzone, G.D. Some environmental conditions affecting yellow eels catchability. Oebalia 1985, 11, 561-571.

7. Chauvet, C. Manuel Sur I Amenagement Des Peches Dans Les Lagunes Cotieres La Bordigue Mediterraneenne Fao Document Technique Sur Les Peches 290; Food and Agriculture Organization of the United Nations (FAO): Rome, Italy, 1988; p. 77.

8. Armenio, E.; De Serio, F.; Mossa, M. Analysis of data characterizing tide and current fluxes in coastal basins. Hydrol. Earth Syst. Sci. 2017, 21, 3441-3454. [CrossRef]

9. De Serio, F.; Mossa, M. Meteo and hydrodynamic measurements to detect physical processes in confined shallow seas. Sensors 2018, 18, 280. [CrossRef] [PubMed]

10. Kjerfve, B. Comparative oceanography of coastal lagoons. In Estuarine Variability; Kennedy, V.S., Ed.; Academic Press: New York, NY, USA, 1986; pp. 63-81.

11. Andréfouët, S.; Pagés, J.; Tartinville, B. Water renewal time for classification of atoll lagoons in the Tuamotu Archipelago (French Polynesia). Coral Reef. 2001, 20, 399-408. [CrossRef]

12. Aubrey, D.G.; Giese, G.S. Formation and Evolution of Multiple Tidal Inlets; American Geophysical Union: Washington, DC, USA, 1993.

13. Papatheodorou, G.; Avramidis, P.; Fakiris, E.; Christodoulou, D.; Kontopoulos, N. Bed diversity in the shallow water environment of Pappas Lagoon in Greece. Int. J. Sediment Res. 2012, 27, 1-17. [CrossRef]

14. Krasakopoulou, E.; Pagou, K. Seasonal steady-state budgets of nutrients and stoichiometric calculations in an Eastern Mediterranean lagoon (Papas Lagoon-Greece). Mediterr. Mar. Sci. 2011, 12, 21-41. [CrossRef]

15. DHI. MIKE C-MAP, Extraction of World Wide Bathymetry Data and Tidal Information. DHI Software, Version 2014. Available online: https://www.mikepoweredbydhi.com/download/mike-by-dhi-2014 (accessed on 15 January 2018).

16. Google Earth Pro, Version 7.3.0.3832. Available online: http://www.google.com/earth/download/ge/ agree.html (accessed on 17 January 2018).

17. National Centre for Marine Research (NCMR). Monitoring of the Papas Lagoon (Cape Araxos/Achaia) Ecosystem-Management and Protection Proposal; Final Technical Report; Pagou, K., Ed.; NCMR: Athens, Greece, 2000; p. 190. 
18. Cladas, Y.; Papantoniou, G.; Bekiari, V.; Fragkopoulu, N. Dystrophic crisis event in Papas Lagoon, Araxos Cape, Western Greece in the summer 2012. Mediterr. Mar. Sci. 2016, 17, 32-38. [CrossRef]

19. DHI. MIKE 3 FLOW MODEL FM. Hydrodynamic Module-User Guide. DHI Software. p. 138. Available online: https://www.mikepoweredbydhi.com/download/mike-by-dhi-2014 (accessed on 15 January 2018).

20. DHI. MIKE 21 FLOW MODEL FM. Hydrodynamic Module-User Guide. DHI Software. p. 132. Available online: https://www.mikepoweredbydhi.com/download/mike-by-dhi-2014 (accessed on 15 January 2018).

21. Fourniotis, N.T.; Horsch, G.M. Baroclinic circulation in the Gulf of Patras (Greece). Ocean Eng. 2015, 104, 238-248. [CrossRef]

22. DHI. MIKE 3 FLOW MODEL FM. Transport Module-User Guide. DHI Software. p. 46. Available online: https:/ / www.mikepoweredbydhi.com/download/mike-by-dhi-2014 (accessed on 15 January 2018).

23. Achilleopoulos, P. Tides in Gulfs and Straits of Western Greece. Ph.D. Thesis, University of Patras, Patras, Greece, 1990.

24. Horsch, G.M.; Fourniotis, N.T. Wintertime Tidal Hydrodynamics in the Gulf of Patras, Greece. J. Coastal Res. 2017, 33, 1305-1314. [CrossRef]

25. Avramidis, P.; Bekiari, V.; Christodoulou, D.; Papatheodorou, G. Sedimentology and water column stratification in a permanent anoxic Mediterranean lagoon environment, Aetoliko lagoon, western Greece. Environ. Earth Sci. 2015, 73, 5687-5701. [CrossRef]

26. Marazioti, C.; Flessia, G.; Vlachos, P.; Koutrouli, E.; Ntaikou, I.; Antonopoulou, G.; Pakou, C.; Kalfas, K.; Kornaros, M.; Lyberatos, G. On the environmental State of the Mesologgi Lagoon in Greece. Fresen. Environ. Bull. 2010, 19, 1151-1164.

27. Papailiou, D.D. Oceanographical Study in Patras Gulf Waters for Pollution Management; University of Patras, Department of Mechanical Engineering: Patras, Greece, 1982; Volume 2, p. 161. (In Greek)

28. Cladas, Y.; Papantoniou, G.; Ketsilis, V.; Fragopoulou, N. Dystrophic crisis event Papas Lagoon (Araxos Achaia). In Proceedings of the 15th Panhellenic Ichthyologists' Conference, Acquatic Ecosystems: Uses, Impact and Management, Thessaloniki, Greece, 2013; pp. 10-13.

29. Monsen, N.; Cloern, J.; Lucas, L.; Monismith, S. A comment on the use of flushing time, residence time and age as transport time scales. Limnol. Oceanogr. 2002, 47, 1545-1553. [CrossRef]

30. Stamou, A.I.; Loverdou, L.; Matsoukis, C.; Albanis, T.; Gkesouli, A. Modeling renewal times in Amvrakikos gulf, Greece. Global NEST J. 2012, 14, 386-392.

31. Ranjbar, M.H.; Zaker, H.N. Numerical modeling of general circulation, thermohaline structure, and residence time in Gorgan Bay, Iran. Ocean Dyn. 2018, 68, 35-46. [CrossRef]

32. Eginitis, D. The problem of the tide of Euripus. Astron. Nachr. 1929, 236, 321-328. [CrossRef]

33. Tsimplis, M.N. Tides and sea-level variability at the Strait of Euripus. Estuar. Coast. Shelf Sci. 1997, 44, 91-101. [CrossRef]

34. Eginitis, D. The problem of the tide of Euripus. Pragmatiai Acad. Athens 1929, A, 127.

35. Gill, A.E. Atmosphere-Ocean Dynamics; Academic Press: San Diego, CA, USA, 1982; p. 662.

36. Li, Y.; Wolanski, E.; Zhang, H. What processes control the net currents through shallow straits? A review with application to the Bohai strait, China. Estuar. Coast. Shelf Sci. 2015, 158, 1-11. [CrossRef]

(C) 2018 by the authors. Licensee MDPI, Basel, Switzerland. This article is an open access article distributed under the terms and conditions of the Creative Commons Attribution (CC BY) license (http:// creativecommons.org/licenses/by/4.0/). 